\title{
Correspondence
}

\section{Venous thromboembolism prophylaxis - beware of potential risks}

Van Zyl et al's study ${ }^{1}$ highlights the importance of increased awareness of venous thromboembolism (VTE) in mental health services for older people. However, it is also important to be aware of the risks of thromboprophylaxis within this setting. The authors claim that the incidence rates of VTE in old age mental health services were comparable with those in general hospitals. However, it does not follow from this that the same approaches for VTE screening and thromboprophylaxis used in general hospitals should be applied, particularly with respect to the risks of thrombocytopenia and bleeding from prophylactic low molecular weight heparin, ${ }^{2}$ which may be exacerbated in mental health in-patient settings, where the average length of stay is likely to be longer than in an acute medical unit. In fact, recent meta-analyses have questioned whether such risks outweigh the potential benefits even within the general hospital setting. ${ }^{3}$ Further evidence should be sought before such VTE prevention strategies are widely implemented in mental healthcare settings, lest they lead to patient harm.

1 van Zyl M, Wieczorek G, Reilly J. Venous thromboembolism incidence in mental health services for older people: survey of in-patient units. Psychiatrist 2013; 37: 283-5.

2 Wang TY, Honeycutt EF, Tapson VF, Moll S, Granger CB, Ohman EM. Incidence of thrombocytopenia among patients receiving heparin venous thromboembolism prophylaxis. Am J Med 2012; 125: 1214-21.

3 Lederle FA, Zylla D, Macdonald R, Wilt TJ. Venous thromboembolism prophylaxis in hospitalized medical patients and those with stroke: a background review for an American College of Physicians Clinical Practice Guideline. Ann Intern Med 2011; 155: 602-15.

Rashmi K. Patel, MRC Clinical Research Training Fellow, Department of Psychosis Studies, King's College London, email: rcpsych@rpatel.co.uk

doi: $10.1192 / \mathrm{pb} .37 .11 .372$

\section{Venous thromboembolism risk assessment in old age psychiatry}

Venous thromboembolism (VTE) risk assessment for patients admitted to old age psychiatric units has been a neglected area. ${ }^{1}$ Both the National Institute for Health and Care Excellence's and the Department of Health's guidelines ${ }^{2,3}$ recommend that every patient admitted to hospital be assessed for VTE and managed appropriately. The failure to adequately screen and prevent VTE is believed to cause annually between 25000 and 32000 potentially avoidable deaths in the UK. ${ }^{4}$

During my 6-month rotation in old age psychiatry, we completed an audit looking into VTE risk assessment for elderly patients. The results were quite alarming: $13 \%$ of patients developed deep vein thrombosis (DVT). We then looked at DVT risk factors retrospectively and this revealed a mean of 3.4 risk factors for patients admitted to our unit. Not one patient had been assessed for VTE or treated on admission with pharmacological prophylaxis or graded compression stockings. Old age psychiatric units do not seem to have policies in place to recognise and manage patients accordingly, in contrast to general hospitals, where every patient undergoes a VTE assessment on admission and is commenced on appropriate prophylaxis immediately.

Unfortunately, both the risks of thrombosis and those associated with prophylactic treatment are increased in frail older people, and this means that careful risk assessment to weigh up the risks and benefits in each patient is essential. A more standardised national approach and greater awareness of the Department of Health's risk assessment tool for $\mathrm{VTE}^{3}$ may be needed.

1 van Zyl M, Wieczorek G, Reilly J. Venous thromboembolism incidence in mental health services for older people: survey of in-patient units. Psychiatrist 2013; 37: 283-5.

2 National Collaborating Centre for Acute and Chronic Conditions. Venous Thromboembolism - Reducing the Risk. Reducing the Risk of Venous Thromboembolism (Deep Vein Thrombosis and Pulmonary Embolism) in Patients Admitted to Hospital (NICE Clinical Guideline 92). NICE, 2010.

3 Department of Health. Venous Thromboembolism (VTE) Risk Assessment (Gateway reference 10278). Department of Health, 2010.

4 Roopen A (ed.) Venous Thromboembolism Prevention: A Patient Safety Priority. King's Thrombosis Centre, 2009.

Abid H. Choudry, CT3 Doctor, Black Country Partnership NHS Foundation Trust, email: abidchoudry@doctors.org.uk

doi: 10.1192/pb.37.11.372a

\section{Diverse response from psychiatrists to CTOs}

I thank Dr Lawton-Smith for his comments on our paper on community treatment orders (CTOs). ${ }^{1,2}$ I find it necessary, however, to emphasise that we never implied that all psychiatrists like the new CTOs. In fact, we merely pointed out that they have been used much more than the Department of Health anticipated. In that sense they have been popular with practising psychiatrists.

We are fully aware that many psychiatrists in England and Wales are uneasy with the legislation. I also agree that the recent Burns et al paper ${ }^{3}$ may well cause a reduction in CTOs used.

1 Lawton-Smith SH. CTOs - use with caution (letter). Psychiatrist 2013; 37: 308

2 Lepping P, Malik M. Community treatment orders: current practice and a framework to aid clinicians. Psychiatrist 2013; 37: 54-7.

3 Burns T, Rugkåsa J, Molodynski A, Dawson J, Yeeles K, Vazquez-Montes $M$, et al. Community treatment orders for patients with psychosis (OCTET): a randomised controlled trial. Lancet 2013; 381: 1627-33.

Peter Lepping, Consultant Psychiatrist and Professor,

Betsi Cadwaladr University Health Board, Bangor University, Wales, email: peter.lepping@wales.nhs.uk

doi: $10.1192 / p b .37 .11 .372 b$

\section{The risk in risk assessment}

Szmukler et al ${ }^{1}$ should be warmly congratulated on their clear, authoritative critique of the recent developments in the law of 